\section{AB0584 PAEDIATRIC VS ADULT ONSET SYSTEMIC LUPUS ERYTHEMATOSUS: THE SIMILARITIES AND DIFFERENCES; A STUDY FROM A TERTIARY CARE CENTRE FROM NORTHERN INDIA ";;}

J. Patel ${ }^{1}$, M. Agarwal ${ }^{2}$, A. Shivpuri ${ }^{2}$, G.S. Bhandari ${ }^{1}$, N. Jain ${ }^{3}$, S. Sawhney ${ }^{2}$, L. Duggal ${ }^{2} .{ }^{1}$ Rheumatology, ${ }^{2}$ Pediatric Rheumatology; ${ }^{3}$ Sir Gangaram Hospital, New Delhi, India

Background: Systemic lupus erythematosus (SLE) is a chronic autoimmune disease with myriad of systemic features. While the disease manifestations and therapy remain same for both paediatric onset(CSLE) and adult onset SLE (aSLE), disease manifestation and burden of disease differs in the two populations.

Objectives: To study disease profile within 6 months of disease onset and burden of disease by SLEDAI of aSLE and CSLE to understand the similarities and differences and to compare with those from around the world

Methods: Retrospective review done of 100 aSLE and cSLE patients, from June 2015 to June 2016, fulfilling SLICC criteria. Demographic data, clinical profile and ds burden at onset(highest of 1 st $6 \mathrm{mths}$ of ds onset) by SLEDAI 2K were recorded on a predesigned proforma

Results: The incidence of skin involvement (acute and chronic cutaneous lupus, alopecia) serositis more in aSLE. Oral mucositis, neuropsychaitric SLE(NPSLE) and lupus nephritis $(L N)$ more common in cSLE.LN was also higher in cSLE from other centres around the world as compared to aSLE. Of statistical significance were non SLICC features like fatigue, Raynaud phenomenon and fatigue in aSLE. CSLE significantly differed in higher incidence of non SLICC features like fever, vasculitic rash and in laboratory features like leucopenia, low complements, dsDNA positivity and antiphospholipid antibody(APLA) positivity. Although APLA antibodies were frequent in CSLE, thrombotic events were rare. On the other hand, thrombotic events were significantly associated with aSLE. Median SLEDAI at onset was higher in CSLE than aSLE. The higher incidence of LN in CSLE than aSLE was similar from the inception cohort from Toronto. ${ }^{1}$ The mean SLEDAl at onset was also similarly higher in CSLE. The spanish SLE registry also reported similar findings. ${ }^{2}$

\section{Abstract AB0584 - Table 1}

\begin{tabular}{|c|c|c|c|c|c|c|c|}
\hline Data at onset & $\begin{array}{l}\text { aSLE(n=100 } \\
1\end{array}$ & $\operatorname{cSLE}(n=100)$ & $\begin{array}{l}\mathbf{P} \\
\text { value }\end{array}$ & SLICC FEATURES & aSLE(\%) & CSLE(\%) & p value \\
\hline Male/ Female & $15 / 85$ & $24 / 76$ & 0.15 & $\begin{array}{l}\text { Acute cutaneous } \\
\text { lupus }\end{array}$ & 67 & 55 & 0.11 \\
\hline $\begin{array}{l}\text { Median Age at } \\
\text { onset }\end{array}$ & $34(9 \cdot 71)$ & $9.5(3.4-17.4)$ & - & $\begin{array}{l}\text { Chronic cutaneous } \\
\text { lupus }\end{array}$ & 07 & 05 & 0.77 \\
\hline $\begin{array}{l}\text { Median Age at } \\
\text { diagnosis(years) }\end{array}$ & $35(9 \cdot 71)$ & $\begin{array}{l}10.25(3.5- \\
19.0)\end{array}$ & - & Mouth ulcer & 46 & 55 & 0.26 \\
\hline $\begin{array}{l}\text { Median delay } \\
\text { to } \\
\text { diagnosis(years) }\end{array}$ & $1(0-15)$ & $0.75(0-5.33)$ & - & Alopecia & 63 & 57 & 0.47 \\
\hline Fever & 57 & 82 &.$^{0.0002}$ & Arthritis & 47 & 65 & $0.015^{*}$ \\
\hline Fatigue & 88 & 57 & 0.0001 & Serositis & 23 & 13 & 0.097 \\
\hline Weight loss & 47 & 33 & 0.06 & $\begin{array}{l}\text { Pleural } \\
\text { effusion/pericardial } \\
\text { effusion }\end{array}$ & 20 & 11 & 0.12 \\
\hline $\mathbf{R P}$ & 39 & 09 & 0.0001 & Lupus nephritis & 26 & 36 & 0.17 \\
\hline Myalgia & 42 & 52 & 0.20 & NPSLE & 13 & 24 & 0.068 \\
\hline Vasculitic rash & 04 & 29 & 0.0001 & Leukopenia & 07 & 25 & 0.0008 \\
\hline $\begin{array}{l}\text { lymphadenopat } \\
\text { hy }\end{array}$ & 27 & 48 & 0.0034 & Thrombocytopenia & 32 & 21 & 0.11 \\
\hline SLEDAI (mean) & 12.9 & 16.59 & - & ANA positivity & 100 & 99 & 1.0 \\
\hline \multirow[t]{6}{*}{ Thrombosis } & 18 & 01 & 0.0001 & $\begin{array}{l}\text { Anti-dsDNA } \\
\text { positivity by If }\end{array}$ & 47 & 77 & 0.0001 \\
\hline & & & & Anti-SM & 24 & 13 & 0.068 \\
\hline & & & & $\begin{array}{l}\text { Anti-cardiolipin } \\
\text { antibody }\end{array}$ & & & $0.028^{x}$ \\
\hline & & & & $\angle A C$ & 09 & 22 & $0.018^{*}$ \\
\hline & & & & Low complements & 41 & 82 & $\begin{array}{l}0.0001 \\
x\end{array}$ \\
\hline & & & & DAI positivity & 31 & 33 & 0.88 \\
\hline
\end{tabular}

Conclusions: This study showed significant difference in initial systemic involvement and onset of presentation in aSLE and CSLE.cSLE present with more subtle features and seldom have a classic presentation with malar rash, oral mucositis and alopecia which oft herald aSLE. CSLE and aSLE though being the same disease often have a varied spectrum of presentation and the generalist and the treating teams need to be aware of these for prompt recognition of the disease and optimum therapy

\section{REFERENCES:}

[1] Brunner HI, Iba nez D, Urowitz MD, SilvermanED. Difference in Disease Features Between Childhood-Onset and Adult-Onset Systemic Lupus Erythematosus. Arthritis and rheumatism.2008;58(2):556-62.

[2] Torrente-Segarra V SMT, Rúa-Figueroa I, Alonso F, López-Longo FJ, Galindo-Izquierdo M, et al. on behalf of the RELESSER Study Group of the Spanish Society of Rheumatology (SER) and the Study Group of
Systemic Autoimmune Diseases of the SER (EAS-SER). Juvenile- and adult-onset systemic lupus erythematosus:a comparative study in a large cohort from the Spanish Society of Rheumatology Lupus Registry (RELESSER). Clinical and Experimental Rheumatology 2017; 35: 1047-1055

Disclosure of Interest: None declared DOI: 10.1136/annrheumdis-2018-eular.5591

\section{AB0585 A LUPUS LOW DISEASE ACTIVITY STATE IS ASSOCIATED WITH REDUCED FLARE, LOWER ORGAN DAMAGE ACCRUAL, AND BETTER QUALITY OF LIFE IN PATIENTS WITH SYSTEMIC LUPUS ERYTHEMATOSUS}

J.-H. Kang, K.-E. Lee, D.-J. Park, S.-S. Lee. Chonnam National University Medical School and Hospital, Gwangju, Korea, Republic of Ireland

Objectives: To identify the potential predictors of a lupus low disease activity state (LLDAS), and the relationship between LLDAS and disease flare, organ damage, and quality of life in Korean patients with systemic lupus erythematosus (SLE).

Methods: The study followed 181 SLE patients from a single centre for three years. LLDAS was defined as follows: ${ }^{1}$ SLE Disease Activity Index (SLEDAI)$2 \mathrm{~K} \leq 4$, with no activity in major organ systems; ${ }^{2}$ no new lupus disease activity com pared with the previous assessment: ${ }^{3}$ SLEDAI Physician Global Assessment $\leq 1 ;{ }^{4}$ a current prednisolone (or equivalent) dose $\leq 7.5 \mathrm{mg}$ daily; and ${ }^{5}$ well-tolerated standard maintenance doses of immunosuppressive drugs. We assessed data annually and divided 4 groups according to the number of LLDAS; LLDAS $=0,1,2$, and 3 . Univariate and multivariate analyses were performed to identify predictors of LLDAS.

Results: Of the 181 patients, $16.0 \%$ attained LLDAS on three consecutive years. Each group shows as follows; no LLDAS $(n=30), \operatorname{LLDAS}=1(n=60)$, LLDAS=2 $(n=62)$, and LLDAS $=3(n=29)$. The patients who had higher number of LLDAS had shorter duration of symptoms, lower anti-histone antibody positivity, lower cumulative prescribed dose of prednisolone at baseline, lower mean PGA, lower mean SLEDAl, lower mean Mental Component Summary in SF-36, lower change in SLICC/ACR damage index, and a lower frequency of flare. In the multivariate analysis, LLDAS was significantly associated with lower mean PGA (OR $=0.671$, $95 \% \mathrm{Cl}: 0.112-0.989, \mathrm{p}=0.019)$ and a reduced risk of flare after adjusting for confounders (OR=0.012, 95\% Cl: $0.001-0.448, \mathrm{p}=0.017$ ).

Conclusions: Attaining LLDAS was associated with an improved outcome, as represented by a decreased rate of disease flare, lower organ damage accrual, and better quality of life in Korean patients with SLE.

Disclosure of Interest: None declared

DOI: 10.1136/annrheumdis-2018-eular.2739

\section{AB0586 CURRENT IMPACT OF ETHNICITY ON RENAL HISTOLOGY AND OUTCOME OF LUPUS NEPHRITIS}

J. Nossent $^{1,2}$, W. Raymond ${ }^{2}$, A. Kang ${ }^{3}$, D. Wong ${ }^{3}$, M. Ognejovic ${ }^{2}$, A. Chakera ${ }^{4,5}$. ${ }^{1}$ Rheumatology, Sir Charles Gairdner Hospital, Nedlands; ${ }^{2}$ Rheumatology, School of Medicine, University of Western Australia, Crawley; ${ }^{3}$ Pathology, PathWest Laboratory Medicine, Nedlands: ${ }^{4}$ School of Medicine, University of Western Australia, Crawley; ${ }^{5}$ Nephrology, Sir Charles Gairdner Hospital, Nedlands, Australia

Background: Lupus Nephritis (LN) remains a serious complication of Systemic Lupus Erythematosus (SLE) and continuous worldwide demographic changes as well as new mechanistic insights and treatment options necessitate regular updating of our knowledge of LN.

Objectives: To investigate the current relevance of demographic, clinical and histological characteristics as outcome predictors in patients with Lupus Nephritis. Methods: A retrospective single centre cohort study of all SLE patients undergoing a first renal biopsy for LN evaluation between 1997-2017 in a metropolitan hospital in Western Australia with a 750.000 catchment area. Demographic, laboratory and treatment data were collected at baseline and at last follow-up using a predefined form and histological findings (ISN class) were re-evaluated. Kaplan Meier survival estimates for patient and renal survival were tested by log-rank test.

Results: The final study cohort included 90 SLE patients (age 31.5 years, $88 \%$ female, time since SLE diagnosis 0.3 years.) of Caucasian $(n=42)$, Asian $(n=30)$, Aboriginal $(n=11)$ and other ethnicity $(n=7$, mainly SubSaharan Africans). The annual LN incidence estimate was $0.6 / 100.000$. There were no significant differences across subgroups regarding renal (overall median 14) and nonrenal SLE DAI (median 4) scores, proteinuria (median PCR $300 \mathrm{mg} / \mathrm{mmol}$ ), presentation with raised serum creatinine ( $31 \%$ overall), anti-dsDNA Ab $(89 \%)$ or hypocomplementemia $(88 \%)$ or presence of proliferative (Class III/IV: $66 \%$ ) or membranous (Class V:19\%) LN. Corticosteroid (86\%), immunosuppressive (87\% overall) and 
antihypertensive drug (69\%) use were similar across ethnic subgroups (all p>0.2) After a mean follow-up of 95 months, eight patients (9\%) had died, six $(7 \%)$ received renal replacement therapy and five (6\%) had developed CKD. Five and ten years patient survival was similar for Asian and Caucasian patients (95\%) and poorest in Aborigines ( $81 \%$ and $70 \%)(p=0.016)$ with no impact of gender, ISN class, full house IF findings or PCR $>300$. Renal 5 and 10 year survival (endpoint RRT) was $100 \%$ for Asian, $100 \%$ and $96 \%$ for Caucasian vs $86 \%$ and $64 \%$ for Aborigines $(p=0.02)$. PCR $>350$ predicted worse renal survival $(p=0.03)$, which was not influenced by gender, increased baseline creatinine, ISN class, A/AC/C subclass or presence of full house IF deposits.

Conclusions: Asian patients have similar clinical and histological LN findings and experience equally good renal and patient outcomes as Caucasian patients in Western Australia, where the incidence rate of $L N$ is comparable with Europe. Whether the grim outlook for Aboriginal patients relates to intrinsic differences in LN pathophysiology and/or socioeconomic circumstances deserves further study. Acknowledgements: Supported by an unrestricted grant from the Arthritis Foundation of Western Australia. We acknowledge the contributions to data collection made by Drs Brandon Wong and Kimberly Minats

Disclosure of Interest: None declared

DOI: 10.1136/annrheumdis-2018-eular.2567

\section{AB0587 HAEMATOLOGICAL ALTERATIONS IN COLOMBIAN PATIENTS WITH SYSTEMIC LUPUS ERYTHEMATOUS}

J. Sanchez-Bautista ${ }^{1}$, Y. Santamaria-Alza ${ }^{2}$, A. Coy-Quiroga ${ }^{2}$, M. Alarcon-Gomez ${ }^{2}$, J. Fajardo-Rivero ${ }^{2}$, C. Figueroa-Pineda ${ }^{2}$, on behalf of Internal medicine department, Industrial University of Santander, Colombia. ' Johns Hopkins University, Baltimore, USA; ${ }^{2}$ Internal medicine, Universidad Industrial de Santander, Bucaramanga, Colombia

Background: Systemic Lupus Erythematosus (SLE) is an autoimmune disease, with multiple organs and system involvement. The most usual haematologica findings are anaemia, leukopenia, and thrombocytopenia. The prevalence of SLE in Colombia was 8.77 per 10000 persons between 2012 and 2016[.

Objectives: To evaluate the haematological alterations in a cohort of patients with SLE in Bucaramanga, Colombia.

Methods: A retrospective cohort study of 149 patients diagnosed with SLE according to the Systemic Lupus International Collaborating Clinics (SLICC) criteria. Descriptive analysis with frequencies, measures of central tendency and dispersion was done using Stata 12.0 software. The primary outcome was the presence of cytopenia, the secondary outcomes were anaemia, leukopenia, and thrombocytopenia. In the group comparison analysis, a chi-square test was used for qualitative variables and Wilcoxon or $T$ student test for quantitative variables according to their distribution. Bivariate analysis using logistic regression with OR measurement, $p$-value, and confidence intervals was performed.

Results: $82.5 \%$ were women, average age was 36.8 years. The primary outcome was found in the $79.8 \%$, anaemia in the $76.5 \%$, thrombocytopenia in the $22.1 \%$ and leukopenia in the $18.7 \%$. In group comparison analysis (cytopenia vs no cytopenia) a statistical difference was found in the variables sex $(p=0.023)$, skin involvement $(p=0.003)$, acute pneumopathy $(p=0.050)$, activity of the disease measured by the ECLAM scale $(p=0.037)$ and anti-DNA antibody titers $(p=0.032)$ In the bivariate analysis, there was an increased risk of cytopenias with statistica significance in male patients (OR: 3.82), ECLAM score greater than 5(OR: 4.75) and strongly positive anti-DNA antibodies (OR: 3.97). Regarding leukopenia there was an association with antiphospholipid syndrome (OR: 2.75), ECLAM greater than 5 (OR: 2.51), SLEDAI MEX greater than 10 (OR: 2.35) and strongly positive anti-DNA antibodies (OR: 2.36). Likewise, an increased risk of mortality was found in patients with leukopenia (OR: 3.92). In the case of thrombocytopenia, an association was found with a pericardial alteration (OR: 2.46), ECLAM greater than 5 points (OR: 3.65), SLEDAI MEX greater than 10 points (OR 2.42). An association with mortality was also observed (OR: 2.97). The risk of presenting anaemia was increased with the variables man (OR: 4.4), ECLAM greater than 5 points (OR: 3.14) and strongly positive anti-DNA antibodies (OR: 3.25).

Conclusions: This is the first Colombian study that evaluates haematological alterations in patients with SLE. The most frequent cytopenia was anaemia. It is possible to identify variables that can predict the appearance of cytopenia, such as the increase in the activity of the disease, which is susceptible to intervention. It is noteworthy that both leukopenia and thrombocytopenia are markers of mortality in patients with SLE.

\section{REFERENCE:}

[1] Fernandez-Avila D, Rincon-Riaño, D (2017) Prevalencia y caractersiticas demograficas del lupus eritematoso sistemico en Colombia, segun informacion del sistema integral de informacion de la proteccion social. Abstrac presentation. Bogotá, Colombia.
Acknowledgements: This research received no specific grant from any funding agency in the public, commercial, or not-for-profit sectors

Disclosure of Interest: None declared

DOI: 10.1136/annrheumdis-2018-eular.7291

\section{AB0588 IDENTIFICATION OF RISK FACTORS FOR HERPES VIRUS INFECTIONS WITH IMMUNOPHENOTYPING DURING INDUCTION THERAPY IN PATIENTS WITH ACTIVE LUPUS NEPHRITIS}

J. Kikuchi ${ }^{1}$, M. Ushikubo ${ }^{2}$, S. Saito ${ }^{1}$, H. Yasuoka ${ }^{1}$, K. Yamaoka ${ }^{1}$, H. Tsujimoto ${ }^{3}$, K. Sugahara ${ }^{3}$, T. Takeuchi ${ }^{1}{ }^{1}$ Division Of Rheumatology, Department Of Internal Medicine, Keio University School of Medicine; ${ }^{2}$ Department of Connective tissue disease, National Hospital Organization Tokyo Medical Center, Tokyo; ${ }^{3}$ Research Unit/Immunology and Inflammation, Mitsubishi Tanabe Pharma Corporation, Kanagawa, Japan

Background: Herpes virus infections (HVIs) including cytomegalovirus infections $(\mathrm{CMVs})$ and herpes zoster $(\mathrm{HZ})$ remains as major complications during treatments with immunosuppressant (IS) in patients with autoimmune diseases. ${ }^{12}$ Previous reports have suggested the associations between virus infections and characteristics of T cells. ${ }^{34}$

Objectives: To elucidate the characteristics of peripheral immune cells associated with risk factors of HVIs during induction therapies in patients with active lupus nephritis (LN)

Methods: Standardised peripheral immunophenotyping was performed using flow cytometry in active $L N$ and ANCA-associated vasculitis (AAV) patients starting induction therapy and also with inactive $L N$ patients with maintenance therapy between April 2015 to April 2017. The definition of HVIs was the infection neces sary to administer anti-viral agents.

Results: Sixty-two LN patients and 11 AAV patients were enrolled. Among 30 active LN patients, 27 were analysed except for 3 patients ( 2 died and 1 withdrawn consent). Mean age was 41.7 years, 9 patients (33\%) had newly-onset, and mean SLE disease activity index (SLEDAI) was 19.3. All active LN patients were treated with prednisolone (PSL) (mean $51.7 \mathrm{mg} /$ day) and 25 were treated with an additional IS (cyclophosphamide [CYC];13, mycophenolate mofetil;8, tacrolimus;3, rituximab [RTX];1). Six (22.2\%) patients developed HVIs (5 CMVs and $1 \mathrm{HZ}$ ) within 3 months following induction therapy. None of the $32 \mathrm{LN}$ patients in maintenance phase (mean age, 54.8; SLEDAI, 2.5; PSL $2.5 \mathrm{mg} /$ day) developed HVls during the mean 2.8 years-observational period. Two (18.2\%) AAV patients developed HVIs within 3 months following induction therapy. All AAV patients (mean age, 64.3) were treated with PSL (mean $41.8 \mathrm{mg} /$ day) and 10 with IS (CYC;5, RTX;3 azathioprine; 1 , methotrexate; 1 .

Among active LN patients, univariate analysis revealed that older age, lower proportions of naïve CD8 $+\mathrm{T}$ cells, higher proportions of effector CD8 $+\mathrm{T}$ cells and HLA-DR +regulatory T cells (Tregs) at baseline and lower naïve CD8 +T cells at month 3 associated with HVIs $(p=0.011, p<0.001, p=0.009, p=0.024, p<0.001$ respectively). Unexpectedly, lymphocyte count, IgG titer, usage of CYC at baseline, renal response and change in SLEDAI at month 3 did not associate with $\mathrm{HVIs}$. Multivariate analysis revealed that low proportions of naïve CD $8+T$ cells and high proportions of HLA-DR +Tregs at baseline were the only detectable independent risk factor for HVIs $(\mathrm{p}=0.014)$

Among AAV patients, univariate analysis showed that older age, lower propor tions of naïve CD8 $+\mathrm{T}$ cells, higher proportions of Tregs at baseline associated with HVIs. However, multivariate analysis showed no independent risk factor for HVIs among them.

Conclusions: Our results suggest that active LN patients with low proportion of naïve CD8 + T cells and high HLA-DR +Tregs at the time of induction therapy should be closely monitored for HVIs. The different results between LN and AAV implicated the different risks of HVIs by immunophenotyping. Larger prospective study is desired to confirm our results.

\section{REFERENCES}

[1] Takizawa Y. et al. Rheumatology (Oxford). 2008;47:1373-8.

[2] Chakravarty EF, et al. Lupus. 2013;22:238-44

[3] Weltevrede M, et al. Exp Gerontol. 2016;77:87-95.

[4] Egli A, et al. PLoS One. 2012;7:e43937.

Disclosure of Interest: J. Kikuchi: None declared, M. Ushikubo: None declared, S Saito: None declared, H. Yasuoka: None declared, K Yamaoka: None declared, H. Tsujimoto Employee of: Mitsubishi Tanabe Pharma Corporation, K Sugahara Employee of: Mitsubishi Tanabe Pharma Corporation, T. Takeuch Grant/research support from: Mitsubishi Tanabe Pharma Corporation DOI: 10.1136/annrheumdis-2018-eular 5202 